\section{The ethics of survival: Teaching the traditional arts to disadvantaged children in post-conflict Cambodia}

\author{
Alexis A. Kallio \\ University of the Arts Helsinki, Sibelius Academy, Finland

\section{Heidi Westerlund} \\ University of the Arts Helsinki, Sibelius Academy, Finland
}

International Journal of Music Education

2016, Vol. 34(I) 90-103 (C) The Author(s) 2015

Reprints and permissior sagepub.co.uk/journalsPermissions.nav DOI: $10.1177 / 0255761415584298$ ijm.sagepub.com

(1)SAGE

\begin{abstract}
Cambodia's recent history of conflict and political instability has resulted in a recognized need to recover, regenerate, preserve and protect the nation's cultural heritage. Many education programmes catering for disadvantaged youth have implemented traditional Khmer music and dance lessons, suggesting that these programmes share the responsibility of cultural regeneration, and view the survival of traditional art forms as dependent on their bequeathal to these young children. In this regard, the musical future of the country is, at least in part, dependent on the success of the vulnerable. However, these vulnerable students are living in a rapidly changing Cambodia, with higher levels of education, increasing international communications and influences, developing infrastructure, urbanization and fundamentally different ways of going about everyday life, work and leisure, to their parents' and grandparents' generations. Through semi-structured individual interviews conducted with Cambodian staff and music, dance and theatre teachers from three music and dance programmes provided by non-governmental organizations catering for vulnerable and disadvantaged young people, we explore how the conflicting objectives of conservation and cosmopolitanism are negotiated and navigated in schools. This study explores themes of conservation, coexistence of multiple traditions and education in wider Cambodian society through performance. These themes are discussed in relation to the ethics of arts teaching, which-whilst intensified in the Cambodian context-are relevant beyond this particular case study.
\end{abstract}

\title{
Keywords
}

Arts education, Cambodia, conservation, ethics, tradition

\section{Corresponding author:}

Alexis A. Kallio, University of the Arts Helsinki, Sibelius Academy, Faculty of Music Education, Jazz and Folk Music/MuTri Doctoral School, PO Box 30, FI-00097 Uniarts, Finland.

Email: alexis.kallio@uniarts.fi 
Contemporary Cambodia may be seen to be caught between two ideal worlds. The first of those worlds is one of conservation and regeneration, rebuilding the ancient cultures and traditions associated with Angkor and the Khmer Empire which were almost eradicated by recent decades of violence and war. The second world is one of progress, as Cambodia is envisioned as a globalized, cosmopolitan nation, politically, economically and also culturally as the country makes strides with a growing market economy, tourism, affordable mass media and communication technology (e.g., Mamula, 2008). In negotiating between these two ideals, significant concerns have been raised (e.g., Sam, 2008) with regards to the teaching and learning of traditional Cambodian music, dance and theatre forms, in both recovering the cultures so damaged by recent history, and participating in an increasingly postmodern world.

Referred to by the United Nations Educational, Scientific and Cultural Organization (UNESCO) as intangible cultural heritage, traditional music, dance and theatre may be seen to form part of the "culture that people practise as part of their daily lives" (Kurin, 2004). According to the 2003 UNESCO Convention for the Safeguarding of the Intangible Cultural Heritage, such intangible cultural heritage includes "music, song, dance, puppetry and theatre, social practices, rituals and festive events" (Kurin, 2004). Intangible cultural heritage has mostly been seen as in need of protection as a result of "the rise of the Information Society, which has proven adept at stripping information from the cultural contexts that give it meaning" (Brown, 2005, p. 40). However, as Brown (2005) notes, globalization cannot be a "convenient scapegoat for anything that seems unjust or disorienting about contemporary life" (p. 43). The importance of music and dance as a matter of "worldwide concern, as well as the ability of advocacy groups to muster international support for heritage protection" (Brown, 2005, p. 43), indeed the existence of the non-governmental organizations (NGOs) participating in this research study, are all examples of globalization's positive effects. However, processes of globalization and increasing cosmopolitanism do raise questions when considering cultural "reproduction (... traditionally referred to in terms of the transmission of culture) ... the problem of enculturation in a period of rapid cultural change" (Appadurai, 1996, p. 43).

The protection of Cambodian music, dance and theatre, among other cultural forms, is not only in peril from globalization, but is additionally vulnerable due to Cambodia's recent social and political history; raising questions about how to safeguard an already vulnerable culture from what may be seen as an immediate, and ever increasing threat. However, in looking to Cambodia's rich ancient past when envisioning the future of the nation's cultural life, "there is no easy way to begin at the beginning" (Appadurai, 1996, p. 64). The question of the future of Cambodian music, dance and theatre traditions becomes even more complex when examined in the context of NGOs for vulnerable young people: How do you teach when knowing that you, as a teacher, may be the last representative of a dying tradition? What do you teach when your own musical repertoire represents only a small part of what used to be a strong orally transmitted art form? What is the role of arts education in such exceptional situations where new audiences must be created alongside new performers? How do you balance the needs of protecting a vulnerable culture, with the needs of protecting vulnerable children? The ethics of teaching are amplified as a result working in a context in which the parameters differ from almost any Western educational setting, intensifying concerns and accelerating the need for action.

\section{Context}

In this context of what may be seen as a cultural crisis, this study addresses what Ayres (2000, p. 440) has described as the crisis of education in Cambodia. According to Ayres (2000), this educational crisis has "resulted from a failure to absorb the competing demands [of] both tradition and 
modernity" (p. 448). As there are few scholarly books or articles that have addressed Cambodian social and cultural life (e.g., Brickell \& Chant, 2010; Kent, 2006) or the country's development, social policies and education (e.g., Ayres, 2000; Hamera, 2002; Locard, 2004; Mamula, 2008; Sam, 2008; Tan, 2007; see also Galto, 2012; Kallio \& Partti, 2013), it is not surprising that there are no studies dealing with the extreme situation of Cambodian music education, as it finds itself between these two crises: that of culture, and that of education. In an attempt to illustrate this context of crisis, in this section we offer a brief outline of the historical and contemporary challenges faced by the arts, and by artists in Cambodia (for a more comprehensive overview of Cambodian political history, see Chandler, 2008).

Between 1863 and 1953, French colonization saw traditional Cambodian education systems (primarily occurring in pagodas and reliant on patronage and clientage, Chandler, 2008) replaced with Western-style schooling systems "intended to socialize selected members of the elite into colonial civil service" (Ayres, 2000, p. 461). During this time, there were only nine high schools, restricted to urban centers (Duggan, 1996), instruction was in French, and literacy in Cambodian languages was almost "entirely in the hands of the Buddhist monkhood" (Chandler, 2008, p. 194). On gaining independence in 1953, King Norodom Sihanouk (1922-2012) embarked on a project of nation-building, with education and culture employed as the means. Consequently, there was a rapid escalation in both the number of schools and teacher colleges, and the University of Phnom Penh was established in 1963 under the direction of a Cambodian national, among other higher education institutions (as means of comparison, Vietnam's first university was opened in 1045, Duggan, 1996). This rapid growth was not without fault, as " $[\mathrm{t}]$ he attitude of the Cambodians ... seemed to be that of the maximum amount of modern education in any field at all for the maximum number of children was an absolute good in itself, without ever taking into account the absorptive capacities of the society" (Vikery, 1985, p. 18), which created challenges as numbers of educated youth were unable to find employment. However, the difficulties faced during these 15 years of "positive educational development" (Ayres, 2000, p. 441) and nation-building, could not compare to those faced in the 1970s; difficulties which heralded the beginning of Cambodia's educational and cultural crises. The exile of King Norodom Sihanouk in 1970, the politically and militarily troubled reign of President Lon Nol (from 1970 to 1975) and the continuing civil war of the early 1970s saw many artists take arms as soldiers (for either the King's army, or Lon Nol's republic forces), eventually to be drawn into the Vietnam war (see Sam, 2008). This essentially halted further developments in education or cultural life, followed by their complete destruction during Pol Pot's Khmer Rouge regime (1975-1979).

During the years 1975 to 1979 education and culture were abolished, and the regime resulted in the deaths of approximately 2.5 million people $-21 \%$ of the then population. Aside from education, intellectualism and professionalism, forbidden practices included religious worship, artistic expression, marriage and family relationships, and discussion of the past (e.g., Mamula, 2008, p. 26). Consequently, both the educated and artists were targeted as part of the Khmer Rouge's extreme communist and nationalist ideologies and auto-genocide, resulting in the deaths of an estimated $95 \%$ of the country's musicians and dancers and $75-80 \%$ of the nation's teachers and higher education students (see also, UNESCO, 2010, p. 24; and Mamula, 2008, p. 26), not to mention the losses of those who fled the country during this period. Following the fall of the Khmer Rouge, Cambodia experienced continued civil conflict during the 1980s under the installation of a Vietnamese-backed government. Accounts of this period vary: "[o]n the one hand, a celebrated period of education renaissance ... [and on the other], a bleak period in Cambodia's history ... [a] silent ethnocide" (Duggan, 1996, p. 366). However, basic education was restored, despite "very poor teaching standards, unqualified teachers and low quality in the provision of a standardised curriculum, texts and facilities" (Duggan, 1996, p. 367). This "chaotic situation" continued well 
into the 1990s, as did widespread corruption practices, such as students or their families bribing teachers for passing grades.

In July 1997 a violent coup d'état again threatened the nation's political stability. Such a tumultuous political and military history has left Cambodia as one of the poorest regions in the world (Royal Government of Cambodia Ministry of Planning, 2006), with education, politics, health systems, food production and cultural life essentially starting from scratch following years of violence and instability. Whilst there have been impressive gains made in Cambodia's education sector, the crisis is not yet over (Ayres, 2000). There is a recognized need to recover, regenerate, preserve and protect the nation's cultural heritage, through the educational reforms directed at young Cambodians, a generation living without (though not unaffected by) such political, social and cultural turmoil.

In contemporary Cambodia, traditional music, dance and theatre lessons primarily occur in the Royal University of Fine Arts, the Secondary School of Fine Arts (both in the capital city Phnom Penh, and with entrance examinations for students), elite training schools, family or small community teaching groups, or pagodas as part of monks' education. This means that with few opportunities and fewer teachers, many Cambodian youth simply do not have the opportunity to access music or dance education. However, a number of NGOs, many of which are financed and overseen by foreigners, have introduced music and dance education programmes. The opportunities offered by these organizations mean that the children cared for by these organizations, in many respects children considered to be disadvantaged, arguably have some of the best access to traditional music and dance education in the country. In this regard, the musical future of the country is, at least in part, dependent on the success of the vulnerable.

However, the conservation of traditional art forms is under the additional pressures of globalization, the NGOs being no exception in this respect. The vulnerable students cared for by these organizations, and their teachers, are living in a rapidly changing Cambodia. Children are now living in a Cambodia with higher levels of education, increasing international communications and influences, developing infrastructure, urbanization and fundamentally different ways of going about everyday life, work and leisure, to their parents' and grandparents' generations. With so few musicians and educators having survived the civil war or the atrocities of the Pol Pot regime, and traditional culture arguably still in a phase of recovery, the future of Cambodian music and dance is precarious. The need to respond to demands of globalization, regionalization and individualization, as identified by national curriculum reforms in Cambodia, "may well be in conflict" (Sam, 2008, p. 94) with the need for preservation of ancient cultural traditions and heritage. Processes of globalization may be seen to further marginalize art forms already rendered fragile by political history. Concerns have been raised regarding how to "pave the way for Cambodia for development and prosperity" (Sam, 2008, p. 98) whilst remaining "generically Khmer" and preserving art forms that not so long ago, the ruling political regime attempted to exterminate.

\section{Research context}

This research project was conducted as part of an ongoing cultural exchange project involving music education masters students, doctoral students and researchers from the Sibelius Academy, University of the Arts Helsinki, Finland. The project, Multicultural Music/Arts University: Promoting understanding and sensitivity through the traditional arts in Cambodia and Finland (2011-2013), aimed to advance ethically sustainable multicultural education and research in both Cambodia and Finland, through collaboratively fostering intercultural understanding and sensitivity in Cambodian educational settings through culturally contextualized teaching, learning and research. The two authors of this article, one a professor of music education and the 
other a music education doctoral candidate at the Sibelius Academy, had each visited Cambodia four times between 2006 and 2013. The Multicultural Music/Arts University project involved three visits to two Cambodian NGOs offering traditional Khmer music, dance and theatre programmes designed for underprivileged, abandoned, orphaned or disabled children. The first NGO consisted of two childcare and education facilities located in Siem Reap, a bustling tourist destination in the north of the country, and the Capital city Phnom Penh. The second NGO was located in a small city in the rural southern coastal region. During the first preparatory visit in August 2011, the authors met organization managers and staff, in preparation for the project the following year, also discussing possible research foci. The second visit, and first round of the project, was in January 2012, and the third visit (second round of the project) in January 2013, when the researchers returned with Finnish masters students and doctoral students for three weeks each visit. Whilst the researchers have remained the same for both visits, the student group has changed, with nine music education masters students and one doctoral student attending the first round of the project, and five music education masters students, one music technology student, and one dance education student attending the second round. As part of the broader project, masters students participated in traditional Cambodian music and dance education programmes and in turn, shared Finnish music and education pedagogies. Researchers conducted a number of studies, focusing on the project as a whole, the students' experiences, and the Cambodian music and dance teachers. The research reported in this article focuses upon the latter, aiming to investigate how music, dance and theatre teachers and NGO staff in the three sites perceive their roles and responsibilities in teaching traditional musics, dance and theatre in an exceptional cultural and educational situation, and, at the same time, an increasingly cosmopolitan Cambodia.

The students taught and/or cared for by the staff in these NGOs were primarily disadvantaged, vulnerable young people, between the ages of five and 20. Some children were orphaned or abandoned due to socioeconomic hardships or diseases (suffered by either their parents or themselves) such as HIV, tuberculosis, hepatitis; removed from their family environments by the government due to extreme domestic violence, substance or sexual abuse; some had families unable to care for them, though were in contact with the children on a regular basis; and some were visiting students from the local community, who whilst without the traumas of many of those who lived in the orphanages themselves, were for other reasons unable to pay for arts education elsewhere. One of the NGOs (the first two sites of research) first introduced music as part of children's broader therapy needs as an optional elective during children's free time. The NGO later offered instruction in both traditional Cambodian and contemporary Western musics and dances including pop/rock, hip hop dance, and a number of Western instruments such as violin, piano, drums, guitar, saxophone etc. The first site cared for approximately 80 children, and the second, approximately 110 children, in addition to running outreach programmes, reintegration programmes and community assistance programmes. The second NGO (the third site of research) was founded as a traditional music and dance school in addition to caring for orphaned children, and thus focused on offering high quality instruction in the traditional arts both to the 31 children living on campus, and to approximately 450 students in the local community outside school hours. The second NGO not only taught traditional music and dance, but also Yike, a theatre form incorporating dance, music and drama that, prior to the 1970s, thrived in the local region. Whilst founded and funded by foreigners, the staff at both organizations were almost all Cambodian. Many of the teachers participating in this study were survivors of the Pol Pot regime, having either fled the country and returned or hidden their education and musical skills during the political uprisings. Others were themselves orphaned and cared for by these organizations, and had returned from further music studies to teach there. The teachers interviewed as part of this study all represented traditional Cambodian music and dance 
forms. The disciplines represented included Pinpeat music, Mahori music, classical dance, folk music and dance, and Yike theatre (see endnotes for a brief description of each discipline). ${ }^{1}$

\section{Research questions and methods}

The research question guiding this study was:

What practical and ethical issues and future visions are raised as the teaching and managerial staff of Cambodian NGOs offering music and dance education to vulnerable young people negotiate and navigate the apparent tensions between the preservation of Cambodian artistic heritage with the development of the country as a cosmopolitan post-conflict society?

This multi-sited, intrinsic case study (Stake, 1995; Yin, 1989) of NGO workers and staff offering music, dance and theatre education in Cambodia, involved semi-structured interviews of approximately 1-2 hours duration conducted in January 2012 with a purposeful sample (Creswell, 1998) of nine music and dance teachers, two managers and the two founders of the NGOs. Teachers were invited to participate in the research through the organization managers, and all of those who agreed and were able to take the time to be interviewed, participated. The majority of music and dance teachers at the first NGO participated in the research, and all music and dance teachers at the second NGO participated in this research. The analysis of the interviews was presented to all participating managers, six teachers and one founder in January 2013 as a means of member-checking, and clarifying research interpretations. Interviews were conducted by both researchers either with individuals (managers or teachers) or in small groups (of up to four teachers), through the assistance of managers who were able to translate between Khmer and English (however, both founders were native English speakers, so were interviewed individually). We acknowledge the limitations of relying on an interpreter, but managers, as cultural and institutional "insiders", were also able to act as cultural interpreters, asking further questions to clarify what it was that was being asked during interviews. In this way, the managers were able to help us negotiate one of the main challenges faced in conducting these interviews, in helping teachers relate interview questions - which focused on the tensions between tradition and globalization - with their day-to-day experiences of teaching. Through the familiarity of managers and teachers with one another, and of life in Cambodian society as an artist, it may be understood that conducting interviews in group settings was a way to approach shared norms and ideals (Sulkunen, 1990, p. 265) and to co-construct meanings (Sherman Heyl, 2001, p. 379).

Interviews focused on the Cambodian teachers' reflections on their own education and backgrounds, their current pedagogies and educational visions (Hammerness, 2006), that is, "images of good practice", guiding choices about curriculum and students and directing reflection on practice (p. xx), and how they understand their roles as arts educators in contemporary Cambodia. The ethical outlines for the study were carefully explained and the participants were able to withdraw from the study at any time. As part of a larger cultural exchange project, the researchers were positioned as participant observers. Whilst the study itself cannot be seen as directly benefiting the local teachers or organizations financially or otherwise, one of the managers expressed how she felt the study would support their own work, music and dance projects:

I also know what is the purpose that you want to do with ... the research, and this research will also give [something to us] ... what we should consider in the future. ${ }^{2}$

This study involved an embedded analysis of the data, focusing on a specific aspect of the casethe tensions between preservation and development. In addition to reading the few available journal articles and books on Cambodian arts and education, observations and interactions with 
staff working at these sites guided questions and functioned as a lens for interpretation (Sherman Heyl, 2001). Through this, we offer a detailed description of the case, in addition to thematic analysis and assertions developed by the researchers (Stake, 1995). Participants' comments and discussions functioned as cues of meanings and cultural constructions (Sulkunen, 1990, p. 275). In this way, the data are therefore not intended as explanatory, but as a starting point for interpretation (Alasuutari, 1995, p. 71), and may form the basis for further research on this topic, and in this particular cultural context.

\section{Concerns, hopes and tensions}

Three central themes were identified in the interviews:

Conservation: a recognition of the vulnerability of different Cambodian cultural traditions, and a strong emphasis on conserving one's own artistic tradition;

Coexistence: an acceptance of other Cambodian and non-Cambodian traditions and cultures existing in their students' lives in parallel to the historically significant ones; and

Community education: an understanding of their students' (and their own) roles in educating the wider community in contemporary Cambodia.

These themes were often discussed in relation to a duty of care they felt towards the vulnerable children these NGOs are responsible for. These three themes will be presented in detail below.

\section{Conservation: Reconstruction and continuation}

All teachers and staff recognized that Cambodian cultural forms were in a fragile state, having suffered, along with the Cambodian people, through the recent decades of trauma. As a result, many saw their roles as conservationists:

The Pol Pot regime ... destroy all the Khmer cultures ... As one of the survivors of the Pol Pot regime, I would like to share what I have learnt so far, and my knowledge related to dancing and art to the next generation. To enable them to know and understand clearly about their culture and traditions. (Dance teacher)

In conserving these vulnerable art forms, an emphasis was placed on teaching and learning music and dances that had been unchanged for generations:

We are very careful to take very good teachers, so what they impart to the students is pure Khmer music, it hasn't been diluted, there are no errors in it. This is very important because the music is from master to pupil, it's not written down. So the children really have had quality teaching and they really learn the Khmer music. (Organization founder)

Indeed, many teachers felt that they could not teach a repertoire that they did not remember perfectly, implying that although a large repertoire existed, perhaps only a limited number of pieces were taught to their students, those that they knew well and were comfortable could be taught in their original form.

This fear of further marginalization and potential loss of traditional music and dance as a result of change, was emphasized as an issue particularly pertinent to contemporary Cambodia. One teacher noted that in her youth, when the culture was perhaps more secure, change and creativity 
were welcomed and encouraged. However, after the devastation of recent decades, such changes are now recognized, at least partially, as a loss or as contributing towards the loss of traditional heritage:

Through my upbringing if we changed something it was good. But in my ... inside, we lost something. We are still thinking that we lost something. (Music teacher)

This effort was seen, not as individual efforts, but rather as a larger national project, in recovering and securing a sense of national identity and pride:

Especially since the war and the Pol Pot days when everything was just shredded to pieces and there was no access to anything cultural or traditional or anything like that. It has been important for their parents to re-establish all of that. I'd say that since the Pol Pot time there is even more of a sense of pride in their traditional musics and dance than before, because before they took it for granted. Now they have to fight to keep it back, especially if you talk to the teachers, they really had to fight to get it back. The children are aware of this. People would have killed to have been a musician or dancer in the Pol Pot days-actually they were killed for that. The kids know that as well. (Organization founder)

... the government don't want to change. They want to keep what is our customs of traditions so far, they want to keep it the same. This is the way we can recognize what is Cambodia. If we change, maybe we cannot recognize this is Cambodia. (Organization manager)

Whilst ensuring the quality and "purity" of the traditional arts was predominantly seen as an internal concern, managers and founders of the NGOs also noted the role of the government in regulating traditional arts education, and a consciousness of being monitored:

Normally for the NGO centers, we need to register once a year that we have Khmer traditional music or dance so it can be acknowledged by the government. Also sometimes they try to organize a big performance and the government invites all of the NGO or centers to perform, so that is the way the government can check that we are doing it right or wrong. (Organization manager)

We've been invited to perform in hotels and so on. When we do, ministry of culture people attend those performances. (Organization founder)

One of the founders noted that a complaint by the ministry of culture had even led to the dismissal of one dance teacher for teaching the dance "incorrectly".

However, whilst it was accepted as important to preserve the music or dance traditions themselves, pedagogies could be altered, improved and developed. This was even the case for musical cultures heavily tied to religious ceremonies and perhaps seen as the more conservative and regulated of musical forms such as Pinpeat music:

The methodology is difficult for the children, so I find better and faster ways for the younger children. (Pinpeat teacher)

Western notation was seen as one way to ensure the preservation of traditional musics, with the ability to notate music seen as a valuable asset:

Our second pinpeat teacher was one of the few musicians who could read notated music, and he taught the students how to write the music down. (Organization founder) 
One of the teachers was also attending further education and training to learn Western notation with the intention of documenting the repertoire he taught, introducing notation skills to others in the organization, and using it as a pedagogical tool with his students.

\section{Coexistence: Traditions, old and new}

Many, if not most, of the children and young people cared for by the two organizations attended classes in multiple Cambodian musical and dance traditions. This was seen, in part, as a way to introduce students to as many art forms as possible, but also to teach them about Cambodia's diverse cultures:

In Cambodia there are many dances, from many minorities and from different parts of the country. The children learn dances and music from different parts of Cambodia, to show one tradition from different areas, like the Pailin Peacock dance. This shows the culture of the people living there, it is a way to learn about different cultures and areas. When they learn they will understand more about the different people in Cambodia. Here we have about 15 dances the dance teacher has taught to our children, so maybe that teaches them about 15 different cultures. (Organization manager)

However, teachers raised concerns over the preservation of individual traditions if an acceptance of plurality jeopardizes specialization and the mastery of any one discipline:

If you are involved in all five [musical] activities, by the time you have finished the end one you are so confused and you forget. It becomes clumsy. (Music teacher)

In solving this dilemma, suggestions from teachers were not to reduce the number of musical or dance traditions on offer, but rather increase the number of students, to establish groups that are able to focus on one specialty:

At this moment we do not lack trainers, but we lack students ... I would like the technical teams. So for pinpeat, only 10 students, only on pinpeat, not involved with Mahori or the others. (Music teacher)

Interviewees acknowledged the introduction of foreign cultural influences as a result of increasing tourism, increasing communication with other nations and increasing availability through media and consumption of other musics, dance styles and cultures. This was not, however, necessarily seen as a threat to the purity and popularity of traditional art forms. Indeed, as observed during the return visit in 2013, a group of young music teachers at one of the NGOs had liaised with a local rock band, and were performing a fusion of rock and traditional musics at a local bar each week. For their students, approaches to other cultural traditions ranged from an acceptance that these could exist in parallel to ancient Cambodian heritage, to envisioning and actively including other traditions in the children's schooling:

We employ a hip hop teacher ... he has experience from TV station, so he is popular for them. He has a new style that he can teach to our children. He is Cambodian. In the future, if we have some other ... style, I think we can exchange. Same as you coming here. We can exchange dances and ideas. (Organization manager)

What I like seeing is how the kids are still very interested and proud of their traditional music and dance and there's not at all any obvious wish to stop it or move away from it. They seem to have a very firm line between the traditional stuff and the Western pop/hip hop stuff. There's been no decline in the attendance 
of the traditional classes, even after we introduced the Western musics. It's a pride thing, a national thing. So although the Western music is emerging - here as well-it hasn't stopped the interest in the traditional stuff. (Organization founder)

However, outside cultures were approached with caution. It was recognized that some aspects of popular and foreign cultures may not be compatible with traditional Cambodian values:

I would like them to know about their culture, and Western cultures' music, I would also like them to know, but not all. The good parts of Western culture, we need to let them know about that. (Dance teacher)

\section{Community education: From the local to the global}

As communities were changed by Cambodia's political history, and are continuing to be changed by increasing globalization, so music and dance teachers understood that part of their, and their students' roles, was to educate the wider community.

When I was [first] here [in this town] they do not like Mahori [music]. We are the ones to preserve the traditions ... so we have to train them how to listen, how to understand the meaning ... We must repeat these actions ... to educate. (Mahori teacher)

One example of these changes may be seen in the modifications to Khmer wedding ceremonies. As Sam-Ang Sam (2007) has noted, traditional weddings were "said to last seven days and nights", which due to economic constraints (among others) "was shortened to three days and nights. Today, it is done in a mere one day and night. While music used to be played almost continuously, day and night, throughout the wedding ceremonies, today, it is heard only in a matter of a few hours. In some instances, sadly live music is substituted by pre-recorded tapes or compact discs" (p. 126). These changes had also been noticed by organization staff:

In the town when I was a child, we used to see the Yike (stories) from $6 \mathrm{pm}$ until 12pm or in the morningwe slept there! They are long stories ... but I do not know the next generation. Even the dancing, if we just do the traditional songs, the older people go to dance, the younger, they do not. (Organization manager)

Through the music and dance programmes offered by these particular NGOs, students had opportunities to represent Cambodian culture, either nationally, or internationally. Student groups had been invited to perform at government functions, community events such as weddings, cultural exchange programmes or fundraising events, and on leaving these organizations, some students had pursued further study abroad. In this way, the students were seen as representing not only the NGOs or their teachers, but Cambodia:

It is important for all of the children, they have to know and understand about their culture, especially when they go abroad. So when foreigners ask them about their culture, if they don't know about their own culture it is a shame. (Music teacher)

They enjoy [performing] and they have a sense of pride I think ... Being what they are, also enables them to travel to show others ... through music these opportunities arise, and they are like cultural ambassadors. They are aware of this I think. (Organization founder)

Whilst children from both NGOs performed regularly both within Cambodia and internationally, staff were very much aware of what the purpose of these performances should and should not be, in considering the ethics of vulnerable children performing in public: 
We try to show this to other people through performance, but we also think about child protection, also using children for labour... Sometimes they go outside also, some outside events that invite our children. We go not because we want to earn money, it is not like that. If they want to give us some money it is okay, but if the children do not want to go, they will not go. It is something for them to practice for, a goal.

(Organization manager)

\section{Conclusions and considerations}

The extreme situation contemporary Cambodian music education is faced with illuminates how the ideals and visions of music education not only need to be culturally understood but also understood as situated in their historical contexts; a view that is often neglected by Western academic discourses. The Cambodian situation in arts education demonstrates how the (re)construction of national cultural heritage unavoidably takes place within and in relation to broader international relationships and increasing globalization. This is particularly visible in Cambodia amongst the younger generation, as they form the majority of the national population. Indeed, the cross-border provision of the project referred to in this article is part of the rapid internationalization of education in the chosen sites and may raise ethical issues of who benefits, and in what ways.

Whilst it is perhaps easy to look from "outside" with recommendations for what should be done in arts education in developing or post-conflict nations, our case study highlights the fact that in such a situation there is no simple solution to the preservation of intangible cultural heritage. In addition, children's education is not the only or necessarily the best arena in which such problems may be addressed, regardless of the strength or vulnerability of the musical culture, or social context. For instance, UNESCO's Roadmap for Arts Education (2006) urges for arts education to incorporate, "where appropriate, traditional pedagogies into the education process with a view to preserving and making full use of culturally appropriate methods of communication and transmission of knowledge" (p. 7, emphasis added). Equally, the Cambodian educators' concerns were very real, and very complex, understanding the role of arts education as more than merely a tool for cultural transmission or reproduction. Interviewees expressed a tension between navigating between the protection of a frail, but valuable past, and Cambodia's ever increasing cosmopolitanism, balancing an acceptance of plurality whilst trying to preserve ancient cultural heritage, and prioritizing the wellbeing and care of the children they taught. Music and dance teachers from the Cambodian NGOs expressed an anxiety and uncertainty on how to fulfil both aims. These tensions are not simply an important consideration but have an impact on the Cambodian teachers' agency; their ability to act in response to, and towards change and the extent to which they are able to focus exclusively on recovering and protecting their musical heritage.

It is also clear that Cambodian music education is faced with ideals that may seem mutually contradictory; ideals that music educators in most Western countries have had decades if not centuries to respond and adapt to. Cambodia is increasingly multicultural (in a global sense), and the children cared for by these organizations are growing up in a cosmopolitan society very different to previous generations. As a result, there is an ethical demand to accept a plurality of cultural traditions. As new musics and dances are made more available through the media, and young people are interested in a variety of musics and cultures, embracing this new knowledge and entertainment is seen as part of the children's care. Indeed it seems absurd to deny a child, particularly one who has already been denied so much, the possibility to identify with and enjoy any music and dance, regardless of its origin. However, at the same time, there is a serious need, and directives from state officials, to preserve Cambodia's historical traditions and especially to recognize the ancient traditions that are directly related to the Khmer identity.

Interestingly, these directives of preservation and authenticity do not apply to all pedagogies. Indeed one music teacher noted that a representative from the Ministry of Culture and Arts had 
introduced him to Solfège. Whilst the artistic ends appear unchanging, revered in what is recognized as their original, undiluted expression, the means to achieve such ends appear somewhat malleable and flexible, with new approaches welcomed pragmatically. This is in apparent contrast with Western academic demands of pedagogical authenticity that purport that "how to teach [music] is fundamentally, inescapably, dependent on what is to be taught" (Regelski, 2006, p. 11). As a whole, the discourse of authenticity (e.g., Volk, 1998, p. 9) in which it is emphasized that ideally music should be taught authentically in close connection to its "original" context, appears problematic, in developing or post-conflict contexts that cannot rely on the luxury of social, political, economic and cultural stability that these approaches assume. Rather, we agree with what teachers seemed to acknowledge, and would argue that it is perhaps more fruitful to reconstruct and re-contextualize traditional art forms in (new) educational settings in order for them to find some security, and hopefully flourish in the future. In thinking beyond this particular situation of recovering one's own music in a new educational context, these findings may also hold implications for "foreign" musics imported into Western classroom contexts (see Schippers, 2010; Westerlund, 2002). In re-contextualizing music, and its teaching and learning, music educators must repeatedly negotiate the tensions between change and preservation. This requires constant reflection and action on behalf of the music educator, regardless of local context, in responding to the preservation of the musical culture, and students' needs to adapt to a changing, globalizing world.

Another suggestion was the introduction and development of Western notation. There were significant concerns regarding the sustainability of the traditional oral means of transmission, and teachers wanted to learn notation as a means to document repertoire and preserve it for future use. Brown (2005) has noted the irony of UNESCO's documentation of intangible cultural heritage through means such as notation:

The convention portrays intangible heritage as an objectified resource amenable to modern management techniques ... the policy is oddly reminiscent of early anthropology ... one struggles to imagine how it will protect cultures as living, dynamic systems. (p. 48)

In the same vein, we too raise questions about the ethics of removing these musics from their community and traditional context in the name of preservation, bestowing them upon an educated elite, only to return them to the communities from which they were taken. This is not to say that notation should not be adopted, but that it should be approached with due consideration. There are equally troublesome questions raised if notation is rejected, as the repertoires may become more and more limited as teachers age and memories are lost.

Although the music, dance and theatre teachers at the NGOs carried responsibility only for teaching their own tradition, they saw themselves not simply as instructors but as educators, and the role of the diverse music and dance traditions, including popular musical cultures such as hip hop, in the lives of their students as educational, even if not included as part of formal lessons. As Bowman (2002) writes when distinguishing education from mere instruction and transmission: "education is distinctively ethical in character, concerned ultimately with the development of character and identity" (p. 64). "The ethical encounter is grounded in commitment, caring, and responsibility" (p. 69) and the truly educational ends are "to nurture the character and dispositions people need to thrive in unpredictable or unforeseeable circumstances" (p. 77). It is important to note that even within such a dire national mission, and with such immediate and serious concerns over their, clearly loved, areas of expertise, the Cambodian teachers began and ended with the students' experience. The vulnerable child was seen always to be the priority, the human ends were more important than the musical achievements. This raises the question: does the context make any difference with regards to the justifications and principles of educating children? From this angle, music education can 
never only serve a wider cultural policy or be aimed towards satisfying cultural or national concerns. Rather, it is always a matter of negotiating these issues within the context of child welfare and growth.

Whilst organizations and teachers clearly contribute not only to children's musical and artistic development, but their more general wellbeing and recovery from traumatic pasts, the concerns raised during these interviews ask important questions about how to ensure such arts education for the Cambodian children of future generations, how to emerge from this state of "crisis":

In the future I feel that I don't know what will happen with [this musical culture], is it getting better or will it be lost? We do not know. If I am not here who will be after me? (Music teacher)

\section{Acknowledgements}

We thank the Ministry of Foreign Affairs for Finland, and the Sibelius Academy for funding this research project.

\section{Funding}

This research received no specific grant from any funding agency in the public, commercial, or not-for-profit sectors.

\section{Notes}

1. Pinpeat music, a music dating back to the 9 th century primarily performing ceremonial or religious music on wind and percussive instruments; Yike theatre is found throughout Cambodia and southern Vietnam, influenced by Cham and Malay cultures, particularly in the singing style reminiscent of Cham and Malay Islamic traditions. Yike consists of both singing and dance, and often incorporates local legends, mythology and humour, performed in local community settings see Cravath (2007); Mahori, a music common to both Thailand and Cambodia, originally court music to be performed by women, though now performed by both men and women. Teachers identified two streams within Mahori: music that was designated for the royal courts, and music that was played primarily at wedding celebrations; Classical dance, for which dancers were traditionally trained from childhood at the Royal Palace, accepted to dance classes from all classes of society, from peasantry to members of the royal family. As both a court dance form and religious-themed repertoire, elaborately costumed dancers were traditionally seen as the earthly counterparts to the entertainers of the Gods, the apsara and devata, and were revered accordingly. Folk music/dance, often depicts scenes of everyday rural Cambodian life and work.

2. Interview participants' discussions, as translated by NGO managers, have been quoted directly. Whilst we understand that the language is not always grammatically correct English, we do not feel it our place to correct them, and do not feel it detracts from understanding the points they wish to convey.

\section{Resources}

Alasuutari, P. (1995). Laadullinen tutkimus. Tampere, Finland: Vastapaino.

Appadurai, A. (1996). Modernity at large: Cultural dimensions of globalization. Minneapolis: University of Minnesota Press.

Ayres, D. M. (2000). Tradition, modernity, and the development of education in Cambodia. Comparative Education Review, 44(4), 440-463.

Bowman, W. (2002). Educating musically. In R. Colwell \& C. Richardson (Eds.), The new handbook of research on music teaching and learning (pp. 63-84). Oxford and New York: Oxford University Press.

Brickell, K., \& Chant, S. (2010). 'The unbearable heaviness of being': Expressions of female altruism in Cambodia, Philippines, Gambia and Costa Rica. Progress in Development Studies, 10(2), 145-159.

Brown, M. (2005). Heritage trouble: Recent work on the protection of intangible cultural property. International Journal of Cultural Property, 12, 40-61. 
Chandler, D. P. (2008). A history of Cambodia. Boulder, CO: Westview Press.

Cravath, P. (2007). Earth in flower: The divine mystery of the Cambodian dance drama. Holmes Beach, FL: DatASIA Inc.

Creswell, J. W. (1998). Qualitative inquiry and research design: Choosing among five traditions. London, UK: Sage.

Duggan, S. J. (1996). Teacher training and prospects for economic recovery in Cambodia. Comparative Education, 32(3), 361-375.

Galto, S. (2012). Education as a form of reconciliation or recognition: Teachers' perspectives on genocide education in Cambodia (Unpublished Master of Arts thesis, Department of Sociology, Northern Illinois University). Retrieved from http://ezproxy.siba.fi/login?url=http://search.proquest.com/docview/10244 32427? accountid $=150397$

Hamera, J. (2002). An answerability of memory: “Saving” Khmer classical dance. The Drama Review, 46(4), $65-85$.

Hammerness, K. (2006). Seeing through teachers' eyes: Professional ideals and classroom practices. New York, NY: Teachers College Press.

Kallio, A. A., \& Partti, H. (2013). Music education for a nation: Teaching patriotic ideas and ideals in global societies. Action, Criticism, and Theory for Music Education, 12(3), 5-30.

Kent, A. (2006). Reconfiguring security: Buddhism and moral legitimacy in Cambodia. Security Dialogue, $37(3), 343-361$.

Kurin, R. (2004). Safeguarding intangible cultural heritage in the 2003 UNESCO Convention: A critical appraisal. Museum International, 56(1-2), 66-77.

Locard, H. (2004). Pol Pot's little red book: The sayings of angkar. Chiang Mai, Thailand: Silkworm Books.

Mamula, S. (2008). Starting from nowhere? Popular music in Cambodia after the Khmer Rouge. Asian Music, $39(1), 26-41$.

Regelski, T. A. (2006). Reconnecting music education with society. Action, Criticism, and Theory for Music Education, 5(2). Retrieved from http://act.maydaygroup.org/articles/Regelski5_2.pdf

Royal Government of Cambodia Ministry of Planning (2006). A Poverty Profile of Cambodia 2004. Retrieved from http://www.mop.gov.kh/Others/PovertyProfile/tabid/191/Default.aspx

Sam, S. (2007). Transmission of Khmer traditional performing arts: Its genuineness, challenge, and impact on society. In Y. Terada (Ed.), Authenticity and Cultural Identity: Senri Ethnological Reports 65, 123-136.

Sam, S. (2008). Arts education in Cambodia: Its social, moral and economic impact. In L. Joubert (Ed.), Educating in the arts: The Asian experience, twenty-four essays. Dordrecht, The Netherlands: Springer.

Schippers, H. (2010). Facing the music: Shaping music education from a global perspective. Oxford: Oxford University Press.

Sherman Heyl, B. (2001). Ethnographic interviewing. In P. Atkinson, A. Coffey, S. Delamont, J. Lofland, \& L. Lofland (Eds.), Handbook of ethnography (pp. 369-383). London: Sage.

Stake, R. (1995). The art of case study research. Thousand Oaks, CA: Sage.

Sulkunen, P. (1990). Ryhmähaastattelujen analyysi. In K. Mäkelä (Ed.), Kvalitatiivisen aineiston analyysi ja tulkinta (pp. 264-285). Helsinki, Finland: Gaudeamus.Tan, C. (2007). Education reforms in Cambodia: Issues and concerns. Educational Research for Policy and Practice, 6(1), 15-24.

United Nations Educational, Scientific and Cultural Organization (UNESCO). (2010). UNESCO National Education Support Strategy, UNESS: Cambodia, 2010-2013. Phnom Penh, Cambodia: Education Unit, UNESCO.

United Nations Educational, Scientific and Cultural Organization (UNESCO). (2006). Roadmap for arts education. Retrieved from http://www.unesco.org/new/fileadmin/MULTIMEDIA/HQ/CLT/CLT/pdf/ Arts_Edu_RoadMap_en.pdf

Vikery, M. (1985). Cambodia: 1975-1982. Boston, MA: South End Press.

Volk, T. (1998). Music, education, and multiculturalism: Foundations and principles. Oxford and New York: Oxford University Press.

Westerlund, H. (2002). Bridging experience, action, and culture in music education (Doctoral dissertation, Sibelius Academy, Helsinki, Finland. Studia Musica 16). Retrieved from http://ethesis.siba.fi/ethesis/ files/isbn9529658982.pdf

Yin, R. K. (1989). Case study research: Design and method. Newbury Park, CA: Sage. 